Published in final edited form as:

J Hum Hypertens. 2017 July ; 31(7): 462-473. doi:10.1038/jhh.2016.98.

\title{
Applying recovery biomarkers to calibrate self-report measures of sodium and potassium in the Hispanic Community Health Study/Study of Latinos
}

\author{
Yasmin Mossavar-Rahmani ${ }^{1}$, Daniela Sotres-Alvarez ${ }^{2}$, William W. Wong ${ }^{3}$, Catherine M. \\ Loria $^{4}$, Marc D. Gellman ${ }^{5}$, Linda Van Horn ${ }^{6}$, Michael H. Alderman ${ }^{1}$, Jeannette M. Beasley ${ }^{7}$, \\ Claudia M. Lora ${ }^{8}$, Anna Maria Siega-Riz ${ }^{9}$, Robert C. Kaplan ${ }^{1}$, Pamela A. Shaw ${ }^{10}$ \\ ${ }^{1}$ Department of Epidemiology \& Population Health, Albert Einstein College of Medicine, Bronx NY \\ (YMR, MHA,RCK) \\ ${ }^{2}$ Collaborative Studies Coordinating Center, Department of Biostatistics, Gillings School of Global \\ Public Health, University of North Carolina at Chapel Hill, NC (DSA) \\ ${ }^{3}$ USDA/ARS, Children's Nutrition Research Center, Department of Pediatrics, Baylor College of \\ Medicine, Houston, TX (WWW) \\ ${ }^{4}$ Division of Cardiovascular Sciences, National Heart, Lung, and Blood Institute, National \\ Institutes of Health, Bethesda, MD (CML-Loria) \\ ${ }^{5}$ Department of Psychology, University of Miami, Coral Gables, FL (MDG) \\ ${ }^{6}$ Department of Preventive Medicine, Feinberg School of Medicine, Northwestern University, \\ Chicago, IL (LVH) \\ ${ }^{7}$ Department of Medicine, New York University, New York, NY (JMB) \\ ${ }^{8}$ Department of Medicine, University of Illinois at Chicago, Chicago, Illinois (CML-Lora) \\ ${ }^{9}$ Departments of Public Health Sciences, University of Virginia, Charlottesville, VA (AMSR) \\ ${ }^{10}$ Department of Biostatistics \& Epidemiology, Perelman School of Medicine, University of \\ Pennsylvania, Philadelphia, PA (PAS)
}

\section{Abstract \\ Measurement error in assessment of sodium and potassium intake obscures associations with health outcomes. The level of this error in a diverse US Hispanic/Latino population is unknown.}

\footnotetext{
Corresponding author: Yasmin Mossavar-Rahmani, Ph.D., Division of Health Promotion \& Nutrition Research, Department of Epidemiology \& Population Health, Albert Einstein College of Medicine. 1300 Morris Park Ave., Belfer Building 1312, Bronx, NY 10461, Tel: 718-430-2136, FAX: 718-430-8780, yasmin.mossavar-rahmani@einstein.yu.edu.

Reprints will not be available from the author

Last names for PubMed indexing: Mossavar-Rahmani, Sotres-Alvarez, Wong, Loria, Gellman, Van Horn, Alderman, Beasley, Lora, Siega-Riz, Kaplan, Shaw.

The content is solely the responsibility of the authors and does not necessarily represent the official views of the National Institutes of Health.

Conflict of interest statement: None of the authors reported any conflicts of interest.

Supplementary Information: Supplementary information is available at the Journal of Human Hypertension website.
} 
We investigated measurement error in self-reported dietary intake of sodium and potassium and examined differences by background (Central American, Cuban, Dominican, Mexican, Puerto Rican and South American).

In 2010-2012, we studied 447 participants aged 18-74 years from four communities (Miami, Bronx, Chicago, and San Diego), obtaining objective 24-hour urinary sodium and potassium excretion measures. Self-report was captured from two interviewer-administered 24-hour dietary recalls. Twenty percent of the sample repeated the study. We examined bias in self-reported sodium and potassium from diet and the association of mismeasurement with participant characteristics. Linear regression relating self-report with objective measures was used to develop calibrations equations.

Self-report underestimated sodium intake by $19.8 \%$ and $20.8 \%$ and potassium intake by $1.3 \%$ and $4.6 \%$ in men and women, respectively. Sodium intake underestimation varied by Hispanic/Latino background $(\mathrm{p}<0.05)$ and was associated with higher body mass index. Potassium intake underestimation was associated with higher BMI, lower restaurant score (indicating lower consumption of foods prepared away from home and/or eaten outside the home), and supplement use. The $\mathrm{R}^{2}$ was $19.7 \%$ and $25.0 \%$ for the sodium and potassium calibration models, respectively, increasing to $59.5 \%$ and $61.7 \%$ after adjusting for within-person variability in each biomarker.

These calibration equations, corrected for subject-specific reporting error, have the potential to reduce bias in diet-disease associations within this largest cohort of Hispanics in the US.

\section{Introduction}

According to NHANES in 2003-2008, $90.7 \%$ of US adults consumed more sodium daily than the IOM Tolerable Upper Intake Level $(2,300 \mathrm{mg})$; however $<2 \%$ of US adults consumed the IOM recommended adequate daily intake for potassium of $\geq 4700 \mathrm{mg}$ (1). Among US adults, mean daily intake for sodium was 3,569 mg and for potassium 2,745 mg $(2,3)$; limited information, however, exists for Hispanic/Latino subgroups other than Mexican-Americans. Measurement error in self-report of sodium and potassium intake has been quantified among five cohort studies (4), but limited data are available among at-risk populations such as Hispanics. This limitation contributes to the uncertainty regarding the relationship of sodium and potassium intake and chronic diseases such as cardiovascular disease and obesity (5-9). The association between high sodium and low potassium intake with elevated blood pressure and hypertension has been consistently demonstrated in randomized, controlled trials as well as observational studies $(2,10,11)$. Disease association studies that rely solely on uncalibrated self-reported dietary exposure data can miss important associations owing to the bias in the self-reported data, whereas biomarker calibrated self-reported exposures can reduce bias to allow for clearer insights into dietdisease relationships (12-14).

Twenty-four hour urinary excretion of sodium and potassium has been the traditional biomarker of intake (15) because about $86 \%$ of sodium and $80 \%$ of potassium is excreted in the urine (16-19). Intakes at the population level have been remarkably consistent across time and place, and have regularly provided a basis for determining associations with physiological and health outcomes. This is almost certainly due to the fact that large sample 
sizes are robust to the random daily variation of individual intakes. For population estimates a sub-sample with multiple measures suffices. Multiple collections of 24-hour urine are usually a better measure of usual intake among individuals. However, the use of 24-hour urinary excretion to assess individual, as opposed to population intake is not without limitations. Consistency of intake, physical activity, ambient heat, humidity and circadian rhythms impact the excretion of sodium and potassium (20) and there may be more variability in potassium than sodium excretion related to racial differences (21). More recently, spot urine collections that take into account timing of collection and race-ethnicity, have also been used, but are reported to be a less accurate estimate than 24-hour urine (20, 22).

In the Women's Health Initiative 24- hour urinary excretion in two subsamples of approximately 500 women each was used to develop calibration equations that corrected the self-report data for random and systematic bias aspects of measurement error $(14,23)$. The equations were used to develop calibrated intake estimates, which adjusted for the error in the self-reported intake, in the Women's Health Initiative study cohorts for use in disease association studies and included pertinent participant characteristics associated with the biases in the self-reported intake. A recent study that compared calibration equations for self-reported potassium and sodium intake across five cohorts (4) found heterogeneity across the cohorts in the calibration coefficients. In this study, the cohorts were predominantly white, college educated ( $81 \%$ in the one study that had the most racial diversity) and calibration equations only allowed for an effect of African American race; the absence of calibration equations based on Hispanic/Latino cohorts highlights the needs to focus on this population

In the Study of Latinos: Nutrition \& Physical Activity Assessment Study (SOLNAS), we collected biomarker and self-report measures of dietary intake in 447 participants from the multi-center Hispanic Community Health Study/Study of Latinos (HCHS/SOL) cohort $(n=16,415)$ to calibrate the self-reported sodium and potassium dietary intake. We quantify the degree to which Hispanic/Latino background (specifically Central American, Cuban, Dominican, Mexican, Puerto Rican, and South American) and other participant characteristics influence the measurement error of self-reported dietary intake. Our ultimate aim is to improve estimates of intake for future use in disease association studies.

\section{Subjects and Methods}

\section{Study population}

HCHS/SOL is a community-based cohort study of 16,415 self-identified Hispanic/Latino adults aged 18-74 years from randomly selected households in four US sites (Chicago, Illinois; Miami, Florida; Bronx, New York; San Diego, California) with baseline examination (2008 to 2011) $(24,25)$ yearly telephone follow-up assessment, and ongoing clinic visit 2 (2014-2017). The baseline clinical examination (24) included comprehensive biological, behavioral, and socio-demographic assessments. Participants were invited to participate in SOLNAS within 7 months of their HCHS/SOL study visit (26). Ineligibility criteria include having any medical condition precluding participation, being pregnant or breastfeeding a child, weight instability (weight loss or gain of $>6.8 \mathrm{~kg}$ in past 4 weeks), 
taking medication for diabetes, or having extended travel plans during the study period. Four hundred eighty five HCHS/SOL participants were enrolled in SOLNAS in 2010-2012.

Enrollment targets at each site were set by specific categories for age, BMI and background to mirror the characteristics of the parent study. The study protocol was approved by the Institutional Review Boards at each of the participating sites and the coordinating/reading centers and all participants provided written informed consent.

\section{Study protocol \& procedures}

As the primary aim of the SOLNAS study was to assess measurement error of self-reported energy and protein intake, the doubly labeled water (DLW) and urinary nitrogen recovery biomarkers were used to assess total energy expenditure (TEE) and protein intake over approximately a 2-wk period (26). Study protocols consisted of two clinic visits with inhome activities between visits (Figure1), and $20 \%$ of the sample (participants who volunteered to repeat the study) repeated the entire protocol approximately six months later. Participants $(n=485)$ arrived for the first visit after a 4-hour fast and provided a baseline urine specimen (pre-DLW spot urine sample). Prior to the second visit, 478 or $98 \%$ of participants collected urine over a 24-hour period, and kept a detailed diary of the number of voids that they missed/spilled. Details of the urine collection measures are described elsewhere (26). Urinary sodium and potassium analyses were performed by ion-selective electrode (Roche Diagnostics, Indianapolis, IN) at HCHS/SOL Central Laboratory at the University of Minnesota. Quality control using blinded duplicate 24-hour urine samples was done on $10 \%(n=49)$ of the cohort. The intra-class correlation coefficient between the blinded duplicate samples for potassium was $0.99, \mathrm{p}<0.001$ and the coefficient of variation was $4.1 \%$. For sodium, the intra-class correlation coefficient from the blinded duplicate samples was $0.99, \mathrm{p}<0.001$ and the coefficient of variation was $3.9 \%$. Biomarker sodium and potassium densities were calculated using TEE per 1,000 kcal.

From the 485 participants enrolled in SOLNAS, 478 completed the $2^{\text {nd }}$ visit, and of those 96 completed the SOLNAS Reliability Study. For the sodium and potassium analyses, we excluded 31 participants from the primary study due to the following reasons (note: some participants excluded for more than one reason): either missing biomarker $(\mathrm{n}=6)$, urine sample $<500 \mathrm{~mL}(\mathrm{n}=10)$, or an inadequate urine sample due to two or more missed collections ( $n=18)$, leaving $n=447$ individuals for analyses (Figure 2). Similarly, from the Reliability Study we excluded 6 participants due to urine sample $<500 \mathrm{~mL}(\mathrm{n}=1)$, or an inadequate urine sample due to two or more missed collections $(\mathrm{n}=5)$. After exclusions, there were 85 individuals with biomarker data in both SOLNAS Primary and Reliability studies.

\section{Statistical analyses}

Self-reported dietary intake was calculated from the mean of the two 24-hour dietary recalls (see supplementary information for description of dietary variables) when both were present (98.6\%), otherwise from the only 24-hour dietary recall available. We used log-transformed consumption estimates for each of potassium, sodium, potassium density and sodium density for statistical analyses. Age-adjusted geometric means for nutrient intakes were calculated and summarized at the mean age (46 years). We assessed the systematic bias of the self- 
report data in relation to participant characteristics using linear regression models on the log (self-report) minus log (biomarker) for sodium and potassium. Because accelerometry data had a high missingness rate of $22.3 \%$, we chose the self-reported version (GPAQ) (27) to enable use of these calibration equations with as many HCHS/SOL participants as possible. The functional form (e.g. linear, polynomial, log, etc.) of continuous covariates (e.g. age, BMI, restaurant score, GPAQ) was assessed bivariately. Then, calibration equations were developed using linear regression models that predicted intake of potassium and sodium by regressing the log-biomarker measure on the corresponding log- self-reported dietary intake and sociodemographic characteristics (age group, Hispanic/Latino background, annual household income, education, employment), acculturation (language of preference, diet acculturation), health behaviors (smoking, alcohol use, supplement use), dietary behaviors (restaurant score, fast food frequency, most meals at home), and indicator variables for each of four types of medications that may impact sodium or potassium excretion (antihypertensives, diuretics, beta blockers, and calcium channel blockers). The percentage of missing values per covariate was extremely low, with only 12 out of 447 participants missing at least one covariate. Stepwise backwards selection was used to select the "best" regression calibration model with a p-value of 0.1 to stay in the model, including only observations without missing values $(n=435)$. Then, the final model selected from the backward model selection was fitted again $(n=446)$ to include back those participants with missing values in other covariates not selected which increases the precision of the estimates.

Partial $\mathrm{R}^{2}$ values (contribution of each covariate to the variance explained by full model) were computed as $\mathrm{R}^{2}$ from the univariate regression of the outcome on the covariate of interest divided by the sum of all univariate $\mathrm{R}^{2}$ and multiplied by the full model $\mathrm{R}^{2}$. The measurement error adjusted ('Prentice') $R^{2}(14)$ for the full model and partial $R^{2}$ were computed by dividing the corresponding $\mathrm{R}^{2}$ by the Pearson correlation between paired biomarkers of SOLNAS Primary Study with the SOLNAS Reliability Study. Lastly, we performed sensitivity analyses for the calibration equations by excluding participants with total urine volume less than 10th percentile. All statistical analyses were conducted using SAS 9.3 software (SAS Institute, Cary, North Carolina).

\section{Results}

Table 1 shows by sex the distribution of participant characteristics, health status, health behaviors, and dietary behaviors (restaurant score, fast food frequency, most meals at home), and medications that may impact sodium or potassium excretion. Overall SOLNAS participants resembled the HCHS/SOL parent study participants in age, BMI, Hispanic/ Latino background, Spanish language preference and education (26). The mean age for the SOLNAS sample was 46.3 years (standard deviation (SD), 13.0) at the baseline HCHS/SOL visit. The mean BMI was $29.7 \mathrm{~kg} / \mathrm{m}^{2}$ (SD, 6.1), with $1.3 \%$ underweight (BMI $<18.5 \mathrm{~kg} / \mathrm{m}^{2}$ ), $18.3 \%$ were normal weight (BMI, 18.5-24.9 $\mathrm{kg} / \mathrm{m}^{2}$ ), $40 \%$ were overweight (BMI 25-29.9 $\mathrm{kg} / \mathrm{m}^{2}$ ) and $40.3 \%$ were obese (BMI $\geq 30 \mathrm{~kg} / \mathrm{m}^{2}$ ). Of the sample $30.2 \%$ were Mexican, 25.7\% were Puerto Rican, $14.5 \%$ were Cuban, $10.5 \%$ were Central American, $10.5 \%$ were Dominican, and $8.5 \%$ were South American. About half (47.6\%) of the participants ((excluding missing data $(\mathrm{n}=38), 8.5 \%$ of total sample)) had an annual household income of $<\$ 20,000$. The mean restaurant score (range $0-36$ ) was 5.3 (SD, 3.9). Overall $76.5 \%$ 
preferred Spanish over English and 26.2\% reported being physically inactive. Women were two times more inactive than men (16.2\%), and the overall mean for self-reported moderate and vigorous physical activity was 108.9 minutes/day (SD, 167.8 minutes/day). Overall 52.8\% abstained from alcohol use; $41.4 \%$ reported eating a mainly Hispanic/Latino diet and ate most meals ( $\geq 68.5 \%$ ) at home. Overall, $18.6 \%$ reported any medication use with $12.3 \%$ reporting anti-hypertensive medications.

Table 2 shows age-adjusted geometric means and 95\% confidence intervals for intake of sodium and potassium as well as their ratios and densities by Hispanic/Latino background. Sodium and potassium mean intakes as assessed by the urinary biomarkers were 3,566 $\mathrm{mg} /$ day and 2,373 mg/day respectively. Cubans $(4,085 \mathrm{mg})$ had the highest sodium intake/day as assessed by biomarker compared to Puerto Ricans $(3,368 \mathrm{mg})$ who had the lowest level. These differences, however, were not statistically significant. The 2-day, 24hour dietary recall mean underestimated absolute sodium and potassium intake and the ratio of sodium to potassium and overestimated density measures of both sodium and potassium. The ratios of self-reported to recovery biomarker (scaled to 100) for sodium were: $79.4 \%$ for absolute and $106 \%$ for density; for potassium: $96.4 \%$ for absolute vs. $128.8 \%$ for density; for sodium to potassium ratio: $82.4 \%$. There were significant differences in the underreporting of sodium intake, and overestimation of potassium density by Hispanic/ Latino background, with Dominicans exhibiting the highest, and the South Americans the lowest level of underreporting of sodium and Puerto Ricans exhibiting the highest and South Americans the lowest level of overestimation of potassium density.

Supplemental Tables 1-3 show age-adjusted geometric means and $95 \%$ confidence intervals for sodium and potassium intake as well as their ratios and densities by BMI, supplement use and the restaurant score, respectively. As indicated urinary sodium and potassium are highest among the obese; however the self-report/biomarker ratio indicates significant underestimation in this group.

Supplement users also exhibit a trend $(P=0.09)$ in underestimating potassium intake. Lastly underestimators of potassium intake have a significantly lower restaurant score (indicating lower consumption of foods prepared away from home and/or eaten outside the home), Table 3 presents regression coefficient (betas) from the linear regression of log (self-report/ biomarker) on socio-demographic, acculturation, behavior and health characteristics to assess systematic bias of the self-report data. Overweight and especially obese (vs. normal and underweight group), and Dominicans ( $v s$. Mexican background) underestimated sodium intake. Also participants with a lower ( $V S$. higher) restaurant score exhibited a trend towards underestimating sodium intake $(P=0.051)$. For potassium intake, the overweight group, obese group ( $v S$. normal and under-weight group), participants with a lower ( $v S$. higher) restaurant score and participants using ( $v S$. not using) a supplement significantly increased underreporting of potassium intake $(P<0.01)$. While the lower restaurant score (indicating lower consumption of foods prepared away from home and/or eaten outside the home) was associated with increased underestimation of potassium intake, participants only stating they never ate fast food (vs. $\geq 3$ times/week) significantly over-estimated potassium intake. 
Table 4 presents the fitted multivariate regression model of $\log$ (biomarker) identified using backward model selection, with intercept representing the reference group mean. For example the reference group for sodium is: males $<25 \mathrm{yr}$, under or normal weight category, consuming the mean sodium intake/day, Spanish language preference, a mean restaurant score, with $\geq 3$ times/week of fast food, and supplement use. The exponentiated regression coefficient represents the change in the ratio of the geometric means of the self-report and urinary biomarkers for a 1 -unit change in the covariate. For sodium intake, BMI $(P<0.001)$, sex $(P<0.001)$ and engaging in moderate to vigorous physical activity $(P=0.028)$ were significant independent predictors of sodium intake. Higher BMI, and engaging in moderate to vigorous physical activity were associated with significant increased sodium intake, while being female was associated with significantly lower sodium intake. For potassium, age $(P<0.022)$, sex $(P<0.001)$, BMI $(P=0.002)$, supplement use $(P<0.001)$, Hispanic/Latino background $(P=0.001)$ and smoking status $(P=0.018)$, were significant independent predictors of intake. Being female, Puerto Rican, and a current smoker, were associated with significant lower potassium intake; whereas using a supplement, being older and obese or overweight was associated with increased potassium intake. The ratio of geometric means for self-reported potassium intake/biomarker was approximately $19 \%$ lower for Puerto Ricans compared with Mexicans, keeping all other factors the same.

Table 5 shows the partial and 'Prentice' adjusted $\mathrm{R}^{2}$ values for the contribution of each covariate to the variance explained by the regression calibration equations for sodium and potassium. The adjusted $\mathrm{R}^{2}$ coefficients took into account the within-person variability in the biomarker using the Pearson correlation between the paired biomarkers of SOLNAS Primary Study with the SOLNAS Reliability Study $(\mathrm{n}=85)$. The $\mathrm{R}^{2}$ for the sodium calibration model was $19.7 \%$ and increased to $59.5 \%$ after adjusting for the within-person variability. Being female was the covariate that explained most of the variance from the full model $(7.6 \%$ which increased to $22.8 \%$ after adjusting for the within-person variability in the biomarker). For the potassium calibration model, the $\mathrm{R}^{2}$ was $25.0 \%$ that increased to $61.7 \%$ after adjusting for the within-person variability in the potassium biomarker. For partial $\mathrm{R}^{2}$ values, self-reported potassium intake had the highest value (6.2\%) that increased to $15.2 \%$ for the adjusted $\mathrm{R}^{2}$ value.

Figure 3 shows scatterplots and correlation coefficients for each nutrient between the primary sample and the reliability sample $(n=85)$ that repeated the entire protocol about 6 months after SOLNAS baseline visit. The reliability of the biomarkers (i.e. the correlation between the paired measures) was $r=0.33$ for sodium, 0.40 for potassium and 0.50 for sodium-to-potassium ratio. The reliability of self-reported nutrients was $r=0.51$ for sodium, 0.48 for potassium and 0.33 for sodium-to-potassium ratio.

A sensitivity analysis was performed to investigate whether excluding observations ( $n=44)$ with extremely low urinary volume (below the $10^{\text {th }}$ percentile), reflecting potential incompleteness of the 24-hour urine collection, influenced the regression calibration coefficients. As presented in Supplemental Table 4, the results were similar to those in Table 4. Supplemental Table 5 shows the partial and adjusted $R^{2}$ for sodium and potassium after excluding 44 participants with total urine volume $<10^{\text {th }}$ percentile. The results were similar 
to Table 5 with slight weakening of the $\mathrm{R}^{2}$ for the potassium for both model and adjusted values.

\section{Discussion}

This is the first study to describe the measurement error structure of sodium and potassium intake estimated from a 24-hour dietary recall compared to urinary biomarkers in a diverse sample of US Hispanics/Latinos. We confirmed the importance of body size to measurement error, as has been shown previously (23). The $\mathrm{R}^{2}$ was $19.7 \%$ and $25.0 \%$ for the sodium and potassium calibration models, respectively, increasing to $59.5 \%$ and $61.7 \%$ after adjusting for the within-person variability in each biomarker. These values are higher than the percentage of biomarker variation explained in the Women's Health Initiative (WHI) study for the 24 hour dietary recall (14.3\% and $27.7 \%$ increasing to $45.6 \%$ and $60.8 \%$ after adjusting for within-person variability for sodium and potassium, respectively) (23) and may reflect the addition of the restaurant score which was not included in the WHI equations. As we did in our prior work to assess impact of low urinary volume (see full discussion in Mossavar-Rahmani et al. (26)), we performed sensitivity analysis by excluding observations with low urinary volumes and did not see significant differences in the coefficients for calibration equations.

Unexpectedly, we found that those participants who less frequently consumed foods prepared away from home significantly underestimated potassium intake and exhibited a trend toward underestimating sodium intake. At the same time participants who only indicated they never ate fast foods ( $v s . \geq 3$ times/week), significantly overestimated potassium intake. These somewhat contradictory findings may be related to the fact that the restaurant score measures a range of eating behaviors such as consuming prepared foods from grocery stores, take-out, bakeries, quick marts, on-street vendors, in addition to eating at fast food restaurants, buffet restaurants and sit-down restaurants. It is also possible that participants who report never frequenting fast food outlets are a group that may perceive their diets to be healthier (higher in potassium) than they are. Additionally the restaurant score used to estimate eating away from home may be a proxy for income. Compared to other studies such as OPEN (4) and WHI biomarker studies $(14,28)$, our participants had relatively low income and less likely to purchase foods prepared outside of the home and /or afford eating out and may have also been challenged in estimating food amounts. As recent immigrants, they may also be less acculturated to the fast food eating pattern of the mainstream US population. In the US and other developed countries, the major source of sodium intake is processed and restaurant foods rather than sodium inherent in foods or salt added at the table or during home cooking; in contrast, salt added during home cooking is the major source of sodium intake in less developed countries (29). It is also possible that the food composition tables underestimate the amount of sodium and potassium in foods cooked at home by our participants. The geometric mean in this study for self-reported sodium intake of 3,436 mg/day in males, and 2,505 $\mathrm{mg} /$ day in females is lower than that reported in the AM/PM study (4) of 4,176 mg/day and 3,184 mg/day respectively using the 24-hour dietary recall. As compared with the AM/PM study (4), SOLNAS participants had similar age, different ethnic background, (AM/PM was primarily non-Hispanic white), and lower educational attainment ( $28 \%$ vs. $54 \%$ college educated) (26). However our mean urinary 
sodium excretion value ( $3,566 \mathrm{mg} /$ day) is comparable to that from a meta-analysis of 38 studies in the US of $3,526 \mathrm{mg} /$ day (30).

The overall geometric mean for self-reported potassium intake of $2,639 \mathrm{mg} /$ day in males, and 2,093 mg/day in females is lower than reported for AM/PM study (4) of 3,402 mg/day and $2,621 \mathrm{mg} /$ day respectively using the 24 -hour dietary recall. With respect to urinary sodium and potassium, the values from our study $(3,566 \mathrm{mg} /$ day for sodium and 2,373 $\mathrm{mg}$ /day for potassium) reflect higher levels of both nutrients compared to data from a sample of New York City adults with weighted mean urinary sodium of 3,395 mg/day and mean urinary potassium of 2,021 mg/day for Hispanics/Latinos (31). The values for potassium are well below the recommendation of $4,700 \mathrm{mg} /$ day.

Compared to other studies the level of underreporting of sodium was somewhat higher. Using a single 24-hour dietary recall, sodium was underreported by $4 \%-13 \%$ in five validation studies (4). On the other hand, the level of misreporting was much higher using the FFQ (5-6\% over-reporting for potassium and 28\%-39\% underreporting for sodium). In a separate study slightly higher levels of bias were seen with web- and duplicate portion based assessments as opposed to telephone-based 24-hour dietary recall (32).

Strengths of this study include an ethnically diverse sample of Hispanic/Latinos in the United States; a wide age range and representation from both sexes. A reliability study consisting of $20 \%$ of the sample who repeated the study about six months later that allowed us to study time-related changes in intake via the adjusted $\mathrm{R}^{2}$. Much of the explained variation for calibrated sodium and potassium came from variables other than the self-report and included BMI, restaurant score and supplement use. These findings underscore the importance of using a calibrated self-report in diet-disease associations with sodium and potassium intake rather than naïve estimates of intake from self-reported instruments which are not adjusted for measurement error.

Limitations of this study include use of single 24-hour urine collection for most participants (26). To limit variability in intake, only weight stable individuals were included in the study. It should be noted that 24-hr urine collection is associated with high participant burden and more so in a low resource population such as HCHS/SOL making repeat collections prohibitive. Only $28 \%$ of our study participants had some college education compared with $86 \%$ of OPEN participants. In the Energetics study, which collected two 24-hr urines, $96 \%$ of participants had a college education or higher (4). We also modeled our protocol on the WHI biomarker studies $(14,28)$ which also collected one 24-hour urine on all participants. Calibration equations in the WHI studies were developed on subsets ( $n=544 \& 450$ respectively) to estimate sodium and potassium intake in all WHI participants $(n=161,000)$.

In addition our sample had smaller numbers of males and some Hispanic/Latinos subgroups such as Central Americans, Dominicans and South Americans and thus our study had limited precision for the regression estimates for these sub-groups. Additional research with larger numbers of these subgroups and better biomarkers for sodium and potassium preferably with lower participant burden is needed. 
Overall the level of sodium underreporting, which varied by Hispanic/Latino background, was higher than that of potassium. It was not possible to disentangle the impact of site from that of Hispanic heritage on misreporting because the recruitment for SOLNAS was such that all Cubans were recruited from Miami, all Dominicans from the Bronx, and all San Diego participants were Mexican.

The unexpected association of a lower restaurant score with significant underestimation of potassium and a trend toward underestimation of sodium is a unique contribution to the literature and may reflect the characteristics of our unique, and primarily immigrant population. We have provided through this study Hispanic/Latino-specific calibration equations for sodium and potassium intake. These calibration equations may be useful in exploring sodium and potassium as exposures when relating diet to health outcomes among Hispanics/Latinos.

\section{Supplementary Material}

Refer to Web version on PubMed Central for supplementary material.

\section{Acknowledgments}

Authors' responsibilities are as follows: YMR and PAS designed the research. YMR, DSA, WWW, MDG and LVH, PAS conducted the research; DSA and PAS analyzed the data. YMR, DSA, WWW, CML (Loria), MDG, LVH, MHA, JMB, CML (Lora), AMSR, RCK and PAS wrote the manuscript. YMR, DSA and PAS had primary responsibility for the final content. All authors have read and approved the final manuscript. YMR, DSA, WWW, CML (Loria), MDG, LVH, MHA, JMB, CML (Lora), AMSR, RCK and PAS reported no conflicts of interest.

Sources of financial support: The Study of Latinos: Nutrition \& Physical Activity Assessment Study was supported by grant R01HL095856 from the National Heart, Lung, and Blood Institute. The Hispanic Community Health Study/Study of Latinos was carried out as a collaborative study supported by contracts from the National Heart, Lung, and Blood Institute to the University of North Carolina (N01-HC65233), University of Miami (N01HC65234), Albert Einstein College of Medicine (N01-HC65235), Northwestern University (N01-HC65236), and San Diego State University (N01-HC65237). The following Institutes/Center/Offices contribute to the Hispanic Community Health Study/Study of Latinos through a transfer of funds to the National Heart, Lung, and Blood Institute: the National Center on Minority Health and Health Disparities, the National Institute of Deafness and Other Communications Disorders, the National Institute of Dental and Craniofacial Research, the National Institute of Diabetes and Digestive and Kidney Diseases, the National Institute of Neurological Disorders and Stroke, and the Office of Dietary Supplements. Additional support at the Albert Einstein College of Medicine was provided from the Clinical \& Translational Science Award (UL1 TR001073) from the National Center for Advancing Translational Sciences at the National Institutes of Health.

We thank the Hispanic Community Health Study/Study of Latinos investigators and staff for their valuable contributions. For a complete list of staff and investigators see: Sorlie P. et al. (24) and http://www.cscc.unc.edu/ hchs/.

\section{References}

1. Cogswell ME, Zhang Z, Carriquiry AL, Gunn JP, Kuklina EV, Saydah SH, et al. Sodium and potassium intakes among US adults: NHANES 2003-2008. Am J Clin Nutr. 2012; 96(3):647-57. [PubMed: 22854410]

2. Zhang Z, Cogswell ME, Gillespie C, Fang J, Loustalot F, Dai S, et al. Association between usual sodium and potassium intake and blood pressure and hypertension among U.S. adults: NHANES 2005-2010. PLoS One. 2013; 8(10):e75289. [PubMed: 24130700]

3. Fulgoni VL 3rd, Agarwal S, Spence L, Samuel P. Sodium intake in US ethnic subgroups and potential impact of a new sodium reduction technology: NHANES Dietary Modeling. Nutr J. 2014; 13(1):120. [PubMed: 25522786] 
4. Freedman LS, Commins JM, Moler JE, Willett W, Tinker LF, Subar AF, et al. Pooled results from 5 validation studies of dietary self-report instruments using recovery biomarkers for potassium and sodium intake. Am J Epidemiol. 2015; 181(7):473-87. [PubMed: 25787264]

5. Alderman MH. Evidence relating dietary sodium to cardiovascular disease. J Am Coll Nutr. 2006; 25(3 Suppl):256s-61s. [PubMed: 16772637]

6. Graudal NA, Hubeck-Graudal T, Jurgens G. Effects of low-sodium diet vs high-sodium diet on blood pressure, renin, aldosterone, catecholamines, cholesterol, and triglyceride (Cochrane review). American Journal of Hypertension. 2012; 25(1):1-15. [PubMed: 22068710]

7. Levings J, Cogswell M, Curtis CJ, Gunn J, Neiman A, Angell SY. Progress toward sodium reduction in the United States. Rev Panam Salud Publica. 2012; 32(4):301-6. [PubMed: 23299292]

8. Murakami K, Livingstone MB, Sasaki S, Uenishi K. Ability of self-reported estimates of dietary sodium, potassium and protein to detect an association with general and abdominal obesity: comparison with the estimates derived from 24 h urinary excretion. Br J Nutr. 2015; 113(8):130818. [PubMed: 25782331]

9. Kieneker LM, Gansevoort RT, de Boer RA, Brouwers FP, Feskens EJ, Geleijnse JM, et al. Urinary potassium excretion and risk of cardiovascular events. Am J Clin Nutr. 2016

10. Cogswell ME, Mugavero K, Bowman BA, Frieden TR. Dietary Sodium and Cardiovascular Disease Risk--Measurement Matters. N Engl J Med. 2016; 375(6):580-6. [PubMed: 27248297]

11. Sacks FM, Svetkey LP, Vollmer WM, Appel LJ, Bray GA, Harsha D, et al. Effects on blood pressure of reduced dietary sodium and the Dietary Approaches to Stop Hypertension (DASH) diet. DASH-Sodium Collaborative Research Group. N Engl J Med. 2001; 344(1):3-10. [PubMed: 11136953]

12. Tinker LF, Sarto GE, Howard BV, Huang Y, Neuhouser ML, Mossavar-Rahmani Y, et al. Biomarker-calibrated dietary energy and protein intake associations with diabetes risk among postmenopausal women from the Women's Health Initiative. Am J Clin Nutr. 2011; 94(6):1600-6. [PubMed: 22071707]

13. Prentice RL, Shaw PA, Bingham SA, Beresford SA, Caan B, Neuhouser ML, et al. Biomarkercalibrated energy and protein consumption and increased cancer risk among postmenopausal women. Am J Epidemiol. 2009; 169(8):977-89. [PubMed: 19258487]

14. Prentice RL, Mossavar-Rahmani Y, Huang Y, Van Horn L, Beresford SA, Caan B, et al. Evaluation and comparison of food records, recalls, and frequencies for energy and protein assessment by using recovery biomarkers. Am J Epidemiol. 2011; 174(5):591-603. [PubMed: 21765003]

15. Mercado CI, Cogswell ME, Valderrama AL, Wang CY, Loria CM, Moshfegh AJ, et al. Difference between 24-h diet recall and urine excretion for assessing population sodium and potassium intake in adults aged 18-39 y. Am J Clin Nutr. 2015; 101(2):376-86. [PubMed: 25646336]

16. Freedman LS, Midthune D, Carroll RJ, Krebs-Smith S, Subar AF, Troiano RP, et al. Adjustments to improve the estimation of usual dietary intake distributions in the population. J Nutr. 2004; 134(7):1836-43. [PubMed: 15226478]

17. Holbrook JT, Patterson KY, Bodner JE, Douglas LW, Veillon C, Kelsay JL, et al. Sodium and potassium intake and balance in adults consuming self-selected diets. Am J Clin Nutr. 1984; 40(4):786-93. [PubMed: 6486085]

18. McCullough ML, Swain JF, Malarick C, Moore TJ. Feasibility of outpatient electrolyte balance studies. J Am Coll Nutr. 1991; 10(2):140-8. [PubMed: 2030256]

19. Clark AJ, Mossholder S. Sodium and potassium intake measurements: dietary methodology problems. Am J Clin Nutr. 1986; 43(3):470-6. [PubMed: 3953485]

20. Cogswell ME, Elliott P, Wang CY, Rhodes DG, Pfeiffer CM, Loria CM. Assessing U.S. sodium intake through dietary data and urine biomarkers. Adv Nutr. 2013; 4(5):560-2. [PubMed: 24038257]

21. Turban S, Miller ER 3rd, Ange B, Appel LJ. Racial differences in urinary potassium excretion. J Am Soc Nephrol. 2008; 19:1396-402. [PubMed: 18579642]

22. Brown IJ, Dyer AR, Chan Q, Cogswell ME, Ueshima H, Stamler J, et al. Estimating 24-hour urinary sodium excretion from casual urinary sodium concentrations in Western populations: the INTERSALT study. Am J Epidemiol. 2013; 177(11):1180-92. [PubMed: 23673246] 
23. Huang Y, Van Horn L, Tinker LF, Neuhouser ML, Carbone L, Mossavar-Rahmani Y, et al. Measurement error corrected sodium and potassium intake estimation using 24-hour urinary excretion. Hypertension. 2014; 63(2):238-44. [PubMed: 24277763]

24. Sorlie PD, Aviles-Santa LM, Wassertheil-Smoller S, Kaplan RC, Daviglus ML, Giachello AL, et al. Design and implementation of the Hispanic Community Health Study/Study of Latinos. Ann Epidemiol. 2010; 20(8):629-41. [PubMed: 20609343]

25. Lavange LM, Kalsbeek WD, Sorlie PD, Aviles-Santa LM, Kaplan RC, Barnhart J, et al. Sample design and cohort selection in the Hispanic Community Health Study/Study of Latinos. Ann Epidemiol. 2010; 20(8):642-9. [PubMed: 20609344]

26. Mossavar-Rahmani Y, Shaw PA, Wong WW, Sotres-Alvarez D, Gellman MD, Van Horn L, et al. Applying Recovery Biomarkers to Calibrate Self-Report Measures of Energy and Protein in the Hispanic Community Health Study/Study of Latinos. Am J Epidemiol. 2015; 181(12):996-1007. [PubMed: 25995289]

27. Hoos T, Espinoza N, Marshall S, Arredondo EM. Validity of the Global Physical Activity Questionnaire (GPAQ) in adult Latinas. J Phys Act Health. 2012; 9(5):698-705. [PubMed: 22733873]

28. Neuhouser ML, Tinker L, Shaw PA, Schoeller D, Bingham SA, Horn LV, et al. Use of recovery biomarkers to calibrate nutrient consumption self-reports in the Women's Health Initiative. Am J Epidemiol. 2008; 167(10):1247-59. [PubMed: 18344516]

29. Anderson CA, Appel LJ, Okuda N, Brown IJ, Chan Q, Zhao L, et al. Dietary sources of sodium in China, Japan, the United Kingdom, and the United States, women and men aged 40 to 59 years: the INTERMAP study. J Am Diet Assoc. 2010; 110(5):736-45. [PubMed: 20430135]

30. Bernstein AM, Willett WC. Trends in 24-h urinary sodium excretion in the United States, 1957-2003: a systematic review. Am J Clin Nutr. 2010; 92(5):1172-80. [PubMed: 20826631]

31. Yi SS, Curtis CJ, Angell SY, Anderson CA, Jung M, Kansagra SM. Highlighting the ratio of sodium to potassium in population-level dietary assessments: cross-sectional data from New York City, USA. Public Health Nutr. 2014; 17(11):2484-8. [PubMed: 24950118]

32. Trijsburg L, de Vries JH, Boshuizen HC, Hulshof PJ, Hollman PC, van 't Veer P, et al. Comparison of duplicate portion and $24 \mathrm{~h}$ recall as reference methods for validating a FFQ using urinary markers as the estimate of true intake. Br J Nutr. 2015; 114(8):1304-12. [PubMed: 26314241]

\section{Abbreviations}

$\begin{array}{ll}\text { BMI } & \text { body mass index } \\ \text { DLW } & \text { doubly labeled water } \\ \text { HCHS/SOL } & \text { Hispanic Community Health Study/Study of Latinos } \\ \text { PABA } & \text { para-aminobenzoic acid } \\ \text { SD } & \text { standard deviation }\end{array}$

SOLNAS Study of Latinos: Nutrition \& Physical Activity Assessment Study

TEE total energy expenditure 


\section{SUMMARY TABLE}

\section{What is known about this topic?}

- $\quad$ Self-reported measures of dietary intake have biases that distort the association of diet and disease

- $\quad$ Biomarker-calibrated measures of self-report can correct error prone measures

- $\quad$ Biases in self-reported measures of sodium and potassium are relatively unexplored in the Hispanic/Latinos population

\section{What does this study add?}

- We present error-corrected self-reported intake estimates of sodium, potassium and their ratio from 24-hour dietary recalls from a diverse US Hispanic/Latino cohort

- These equations were developed by comparing against biomarker data and adding pertinent participant characteristics that help increase the signals from self-reported data

- $\quad$ Error-corrected self-reported intake intake from these calibration equations will be used for diet disease association analyses to more precisely understand the role of sodium and potassium in affecting health outcomes 


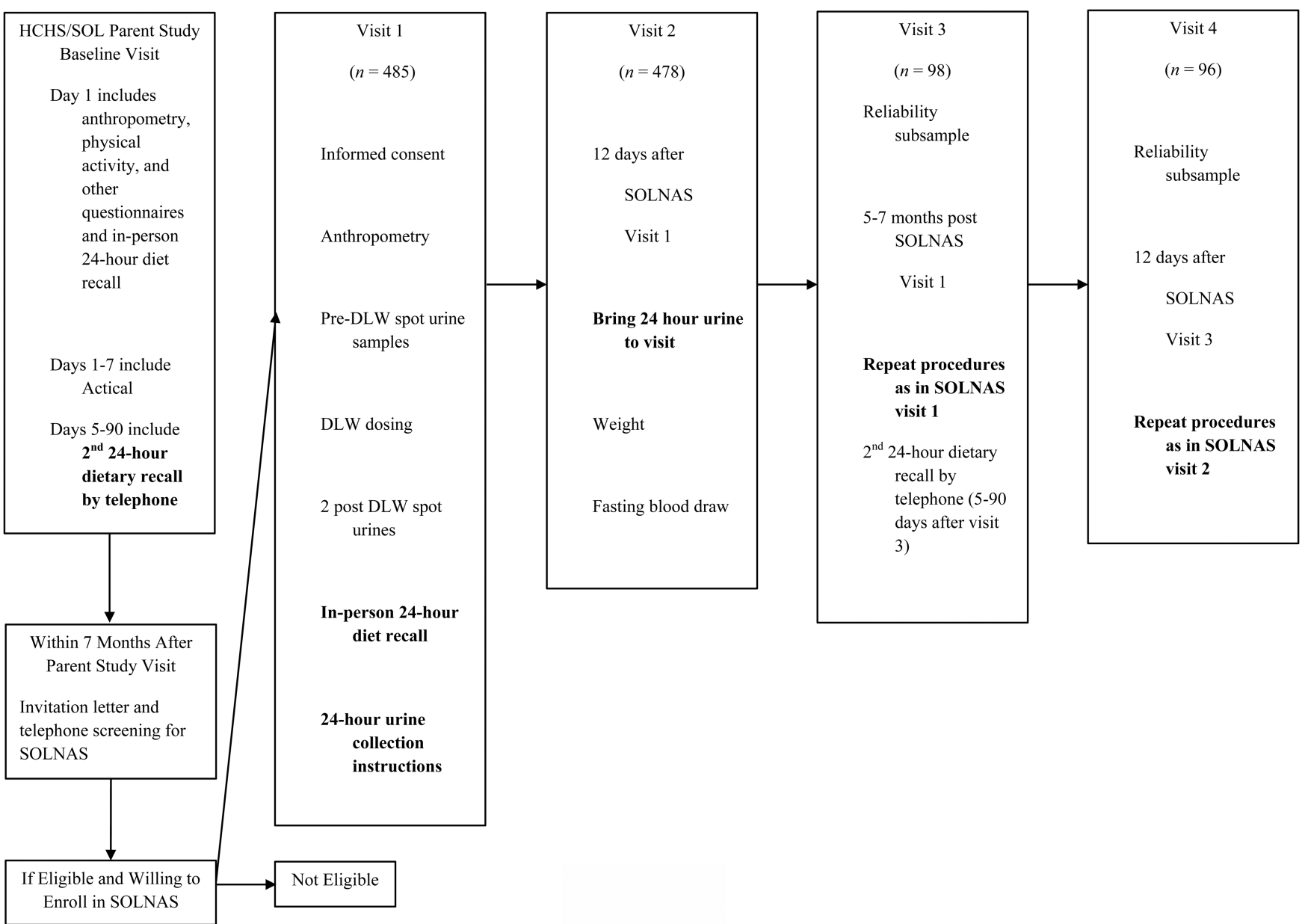

Figure 1.

Study of Latinos: Nutrition and Physical Activity Assessment Study (SOLNAS) procedures, 2010-2012. Invitation letter and telephone screening for SOLNAS occurred up to 12 months after the parent study visit for the San Diego site (26). DLW, doubly labeled water; GPAQ, Global Physical Activity Questionnaire; HCHS, Hispanic Community Health Study; SOL, Study of Latinos. Actical is an accelerometer that converts accelerations to a unit called “counts" over a given time period (1 minute) (Phillips Respironics, Bend, Oregon). Bolded items relate to collection of urinary sodium/potassium. Adapted from Mossavar-Rahmani et al. (26) 


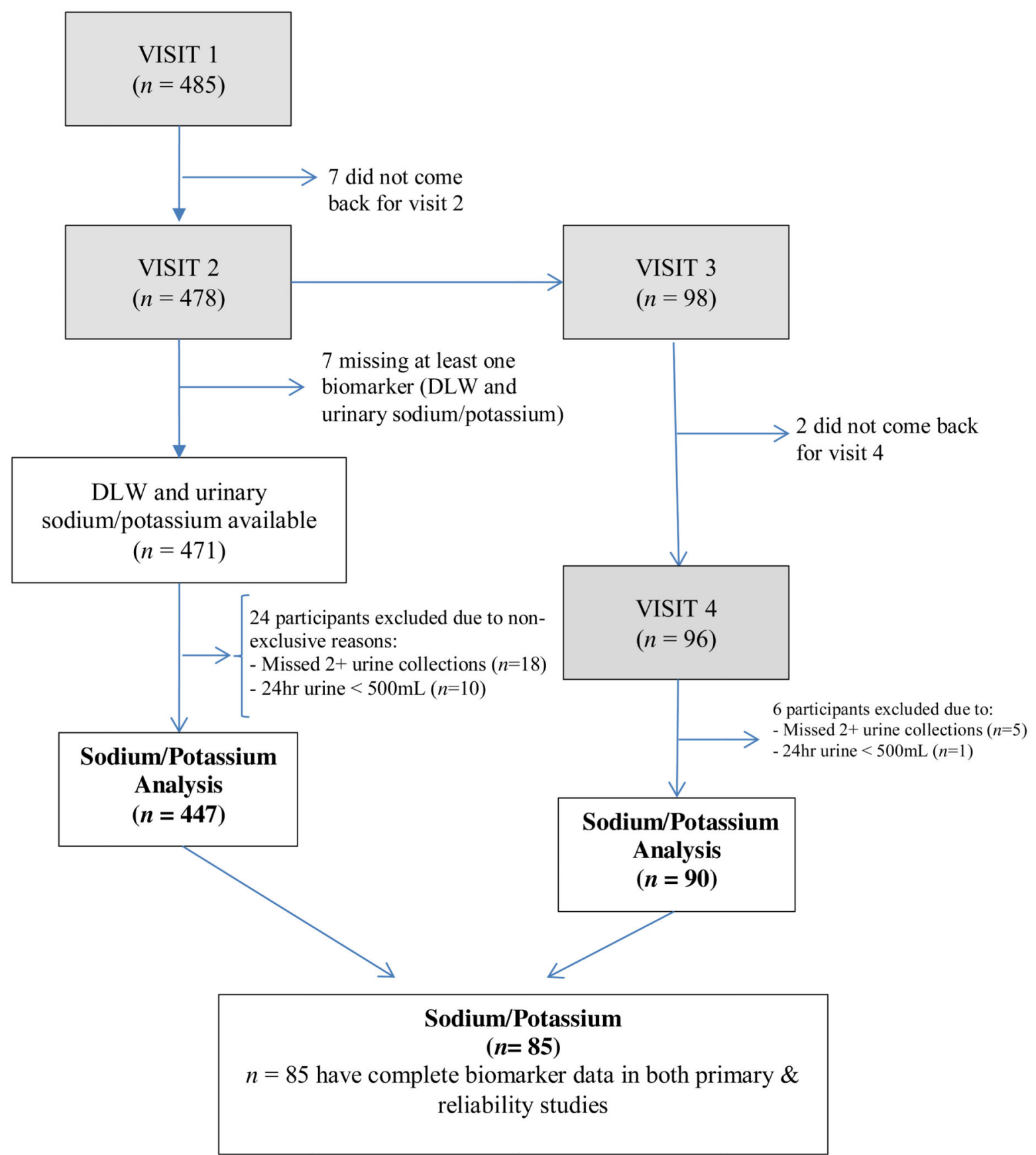

Figure 2.

Flow chart of enrolled study subjects from enrollment to completion of study, Study of Latinos: Nutrition and Physical Activity Assessment Study, 2010-2012. 
A)

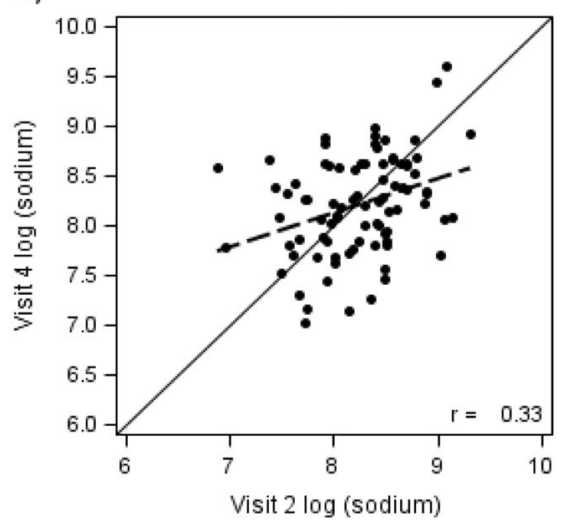

D)

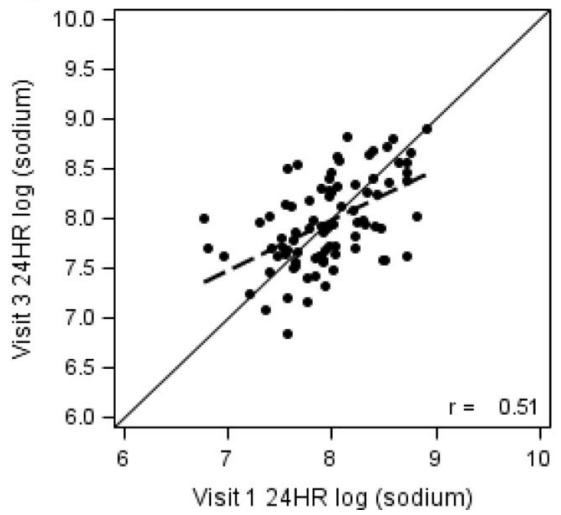

B)

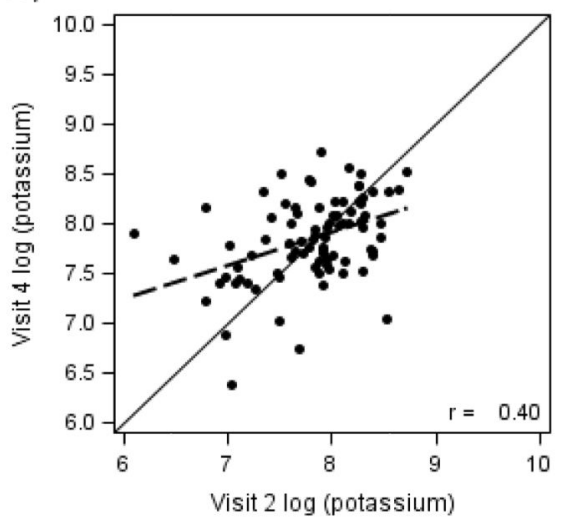

E)

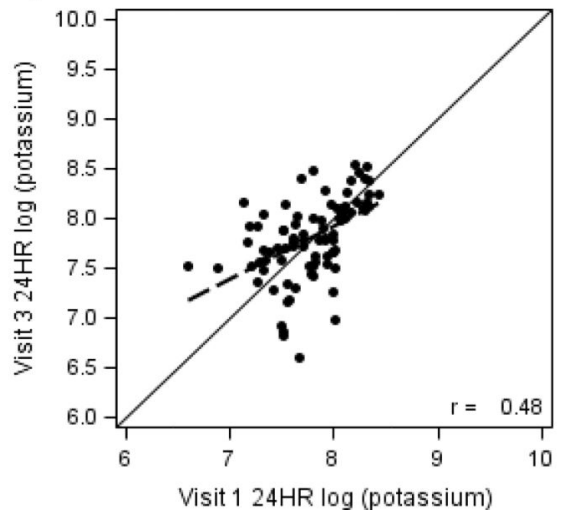

C)

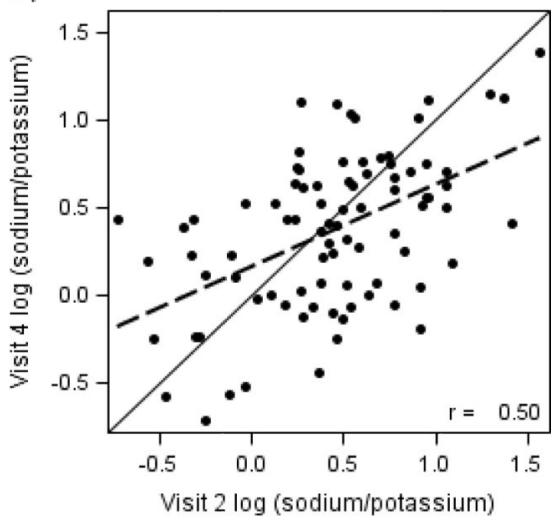

F)

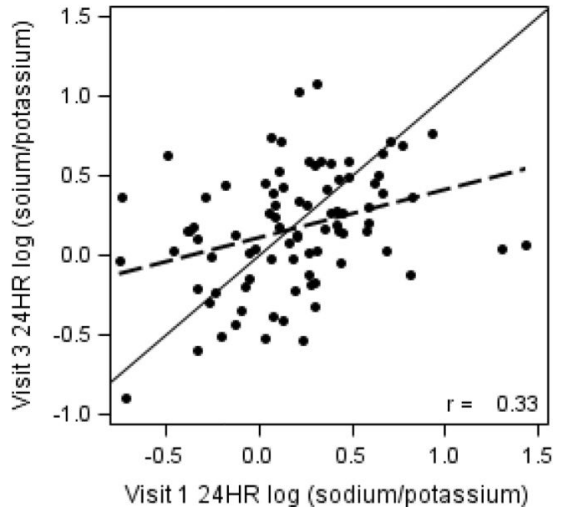

Figure 3.

Comparison of the logarithm ( $\log )$ of visits 2 and 4 measures $(n=85)$ for the biomarker and visits 1 and 3 for the self-reported 24-hour recall assessments (24HR). Study of Latinos: Nutrition and Physical Activity Assessment Study, 2010-2012 (26). a) Biomarker sodium (log-mg); b) Biomarker potassium (log-mg); c) Biomarker sodium/potassium (log scale); d) Self-reported sodium; e) Self-reported potassium; f) Self-reported sodium-to-potassium ratio. Visit $124 \mathrm{HR}$ is the mean of HCHS/SOL 24HR recall by telephone and SOLNAS visit 1 in-person 24HR recall; Visit 3 24HR is the mean of SOLNAS Visit 3 in person 24HR recall and SOLNAS Visit 3 telephone 24HR recall. 
TABLE 1

Demographic and Lifestyle Characteristic of Participants in the Study of Latinos: Nutrition \& Physical Activity Assessment Study, by Sex, 2010-2012 ${ }^{1}$

\begin{tabular}{|c|c|c|c|c|}
\hline \multirow[b]{2}{*}{ Characteristic } & \multicolumn{2}{|c|}{ Overall $(n=447)$} & \multirow{2}{*}{$\begin{array}{c}\operatorname{Men}(\mathbf{n}=173) \\
\%\end{array}$} & \multirow{2}{*}{$\begin{array}{c}\text { Women }(\mathbf{n}=274) \\
\%\end{array}$} \\
\hline & Sample Size & $\%$ & & \\
\hline \multicolumn{5}{|l|}{ Age group, years } \\
\hline $18-24$ & 36 & 8.1 & 11.6 & 5.8 \\
\hline $25-39$ & 87 & 19.5 & 20.2 & 19.0 \\
\hline $40-54$ & 197 & 44.1 & 42.8 & 44.9 \\
\hline $55-74$ & 127 & 28.4 & 25.4 & 30.3 \\
\hline \multicolumn{5}{|l|}{ BMI group 2} \\
\hline Underweight $(<18.5)$ & 6 & 1.3 & 1.7 & 1.1 \\
\hline Normal (18.5-24.9) & 82 & 18.3 & 19.1 & 17.9 \\
\hline Overweight (25-29.9) & 179 & 40.0 & 42.2 & 38.7 \\
\hline Obese ( $\geq 30)$ & 180 & 40.3 & 37.0 & 42.3 \\
\hline \multicolumn{5}{|l|}{ Language of preference } \\
\hline Spanish & 342 & 76.5 & 69.4 & 81.0 \\
\hline English & 105 & 23.5 & 30.6 & 19.0 \\
\hline \multicolumn{5}{|l|}{ Hispanic/Latino background } \\
\hline Central American & 47 & 10.5 & 11.0 & 10.2 \\
\hline Cuban & 65 & 14.5 & 16.8 & 13.1 \\
\hline Dominican & 47 & 10.5 & 10.4 & 10.6 \\
\hline Mexican & 135 & 30.2 & 26.6 & 32.5 \\
\hline Puerto Rican & 115 & 25.7 & 27.7 & 24.5 \\
\hline South American & 38 & 8.5 & 7.5 & 9.1 \\
\hline \multicolumn{5}{|l|}{ Yearly household income } \\
\hline Missing & 38 & 8.5 & 8.7 & 8.4 \\
\hline$\$ \$ 10,000$ & 64 & 14.3 & 11.6 & 16.1 \\
\hline$\$ 10,001-\$ 20,000$ & 149 & 33.3 & 30.1 & 35.4 \\
\hline$\$ 20,001-\$ 40,000$ & 133 & 29.8 & 32.4 & 28.1 \\
\hline$\$ 40,001-\$ 50,000$ & 34 & 7.6 & 8.1 & 7.3 \\
\hline$\$ 50,001-\$ 75,000$ & 19 & 4.3 & 4.6 & 4.0 \\
\hline$>\$ 75,000$ & 10 & 2.2 & 4.6 & 0.7 \\
\hline \multicolumn{5}{|l|}{ Education status } \\
\hline Less than high school & 141 & 31.5 & 25.4 & 35.4 \\
\hline High school or equivalent (GED) & 112 & 25.1 & 27.7 & 23.4 \\
\hline Trade/Vocational school & 67 & 15.0 & 12.7 & 16.4 \\
\hline University/College & 127 & 28.4 & 34.1 & 24.8 \\
\hline \multicolumn{5}{|l|}{ Employment status } \\
\hline Employed full-time & 36 & 8.1 & 9.8 & 6.9 \\
\hline Employed part-time & 204 & 45.6 & 37.6 & 50.7 \\
\hline Not retired and not employed & 85 & 19.0 & 15.6 & 21.2 \\
\hline
\end{tabular}




\begin{tabular}{|c|c|c|c|c|}
\hline \multirow[b]{2}{*}{ Characteristic } & \multicolumn{2}{|c|}{ Overall $(n=447)$} & \multirow{2}{*}{$\begin{array}{c}\operatorname{Men}(\mathbf{n}=173) \\
\%\end{array}$} & \multirow{2}{*}{$\begin{array}{c}\text { Women }(n=274) \\
\%\end{array}$} \\
\hline & Sample Size & $\%$ & & \\
\hline Retired and not employed & 122 & 27.3 & 37.0 & 21.2 \\
\hline \multicolumn{5}{|c|}{ Activity level ${ }^{3}$ per 2008 physical activity guidelines } \\
\hline Inactive & 117 & 26.2 & 16.2 & 32.5 \\
\hline Low & 56 & 12.5 & 9.8 & 14.2 \\
\hline Moderate & 43 & 9.6 & 8.7 & 10.2 \\
\hline High & 231 & 51.7 & 65.3 & 43.1 \\
\hline \multicolumn{5}{|l|}{ Alcohol use/drinking level ${ }^{4}$} \\
\hline No current use & 236 & 52.8 & 40.5 & 60.6 \\
\hline Low level use & 190 & 42.5 & 50.9 & 37.2 \\
\hline High level use & 21 & 4.7 & 8.7 & 2.2 \\
\hline \multicolumn{5}{|l|}{ Current smoker } \\
\hline No & 354 & 79.2 & 77.5 & 80.3 \\
\hline Yes & 92 & 20.6 & 22.0 & 19.7 \\
\hline \multicolumn{5}{|l|}{ Supplement use } \\
\hline No & 230 & 51.5 & 53.8 & 50.0 \\
\hline Yes & 217 & 48.5 & 46.2 & 50.0 \\
\hline \multicolumn{5}{|l|}{ Type of food } \\
\hline Mainly Hispanic/Latino food & 185 & 41.4 & 38.2 & 43.4 \\
\hline Mostly Hispanic/Latino food & 140 & 31.3 & 30.6 & 31.8 \\
\hline Equal amount Hispanic/American food & 100 & 22.4 & 24.3 & 21.2 \\
\hline Mostly or mainly American food & 21 & 4.7 & 6.9 & 3.3 \\
\hline \multicolumn{5}{|l|}{ Eat fast food } \\
\hline Never & 136 & 30.4 & 31.8 & 29.6 \\
\hline$<1$ per week & 137 & 30.6 & 28.3 & 32.1 \\
\hline 1-2 times per week & 141 & 31.5 & 31.2 & 31.8 \\
\hline 23 times per week & 32 & 7.2 & 8.7 & 6.2 \\
\hline \multicolumn{5}{|l|}{ Most meals at home ( $\geq 75 \%)$} \\
\hline No & 141 & 31.5 & 42.2 & 24.8 \\
\hline Yes & 306 & 68.5 & 57.8 & 75.2 \\
\hline \multicolumn{5}{|l|}{ Any medication use (including steroids) } \\
\hline No & 364 & 81.4 & 80.9 & 81.8 \\
\hline Yes & 83 & 18.6 & 19.1 & 18.2 \\
\hline \multicolumn{5}{|l|}{ Anti-hypertensive medications } \\
\hline No & 382 & 85.5 & 84.4 & 86.1 \\
\hline Yes & 55 & 12.3 & 14.5 & 10.9 \\
\hline \multicolumn{5}{|l|}{ Beta blockers } \\
\hline No & 421 & 94.2 & 94.8 & 93.8 \\
\hline Yes & 16 & 3.6 & 4.0 & 3.3 \\
\hline \multicolumn{5}{|l|}{ Calcium channel blockers } \\
\hline No & 422 & 94.4 & 95.4 & 93.8 \\
\hline Yes & 15 & 3.4 & 3.5 & 3.3 \\
\hline
\end{tabular}




\begin{tabular}{|c|c|c|c|c|}
\hline \multirow[b]{2}{*}{ Characteristic } & \multicolumn{2}{|c|}{ Overall $(n=447)$} & \multirow{2}{*}{$\begin{array}{c}\operatorname{Men}(\mathbf{n}=173) \\
\%\end{array}$} & \multirow{2}{*}{$\begin{array}{c}\text { Women }(n=274) \\
\%\end{array}$} \\
\hline & Sample Size & $\%$ & & \\
\hline \multicolumn{5}{|l|}{ Diuretics } \\
\hline No & 407 & 91.1 & 93.1 & 89.8 \\
\hline Yes & 30 & 6.7 & 5.8 & 7.3 \\
\hline Restaurant score ${ }^{5}$ (range: 0 to 36 ) & 447 & $5.3 \pm 3.9^{6}$ & $5.9 \pm 4.2$ & $4.9 \pm 3.6$ \\
\hline Physical activity (self-report), $\mathrm{min} / \mathrm{day}$ & 447 & 108.9(167.8) & $154.7(198.8)$ & $80.0(137.7)$ \\
\hline
\end{tabular}

Abbreviations: BMI, body mass index; GED, General Educational Development (test)

${ }^{1}$ Based on the Hispanic Community Health Study/Study of Latinos parent study baseline visit

$2_{\text {BMI expressed as } \mathrm{kg} / \mathrm{m}^{2}}$

3

elf-reported physical activity in a typical week, assessed using an interviewer-administered modified Global Physical Activity Questionnaire (available at https://www2.cscc.unc.edu/hchs/system/files/forms/UNLICOMMPhysicalPAE02182008.pdf). The 2008 Physical Activity Guidelines for Americans are available at http://www.health.gov/paguidelines/guidelines/. High activity was defined with more than the equivalent of 300 minutes of moderate-intensity physical activity a week, or more than 150 minutes of vigorous activity, or an equivalent combination of both. Medium activity was defined as 150 minutes to 300 (5 hours) minutes of moderate-intensity activity a week (or 75 to 150 minutes of vigorousintensity physical activity a week) or the equivalent combination of moderate and vigorous activity. Low activity was defined as activity beyond baseline but fewer than 150 minutes ( 2 hours and 30 minutes) of moderate-intensity physical activity a week or the equivalent amount (75 minutes, or 1 hour and 15 minutes) of vigorous-intensity activity" or the equivalent combination of moderate and vigorous activity. Inactive was defined as no activity beyond baseline activities of daily living

${ }^{4}$ Low level use: current use <14 drinks/week; current high level use: $\geq 14$ drinks/week.

5 Higher values indicate more frequently going out to eat or bringing home ready-to-eat foods

${ }^{6}$ Mean \pm SD

Sample sizes that differ from 447due to sporadic missing data are for the categories: Current smoker; Types of Food; Eats Fast Food; each category has $n=446$.

For the following categories: Anti-hyptertensive medications, beta blockers, calcium channel blockers, diuretics, each category has n=437. 


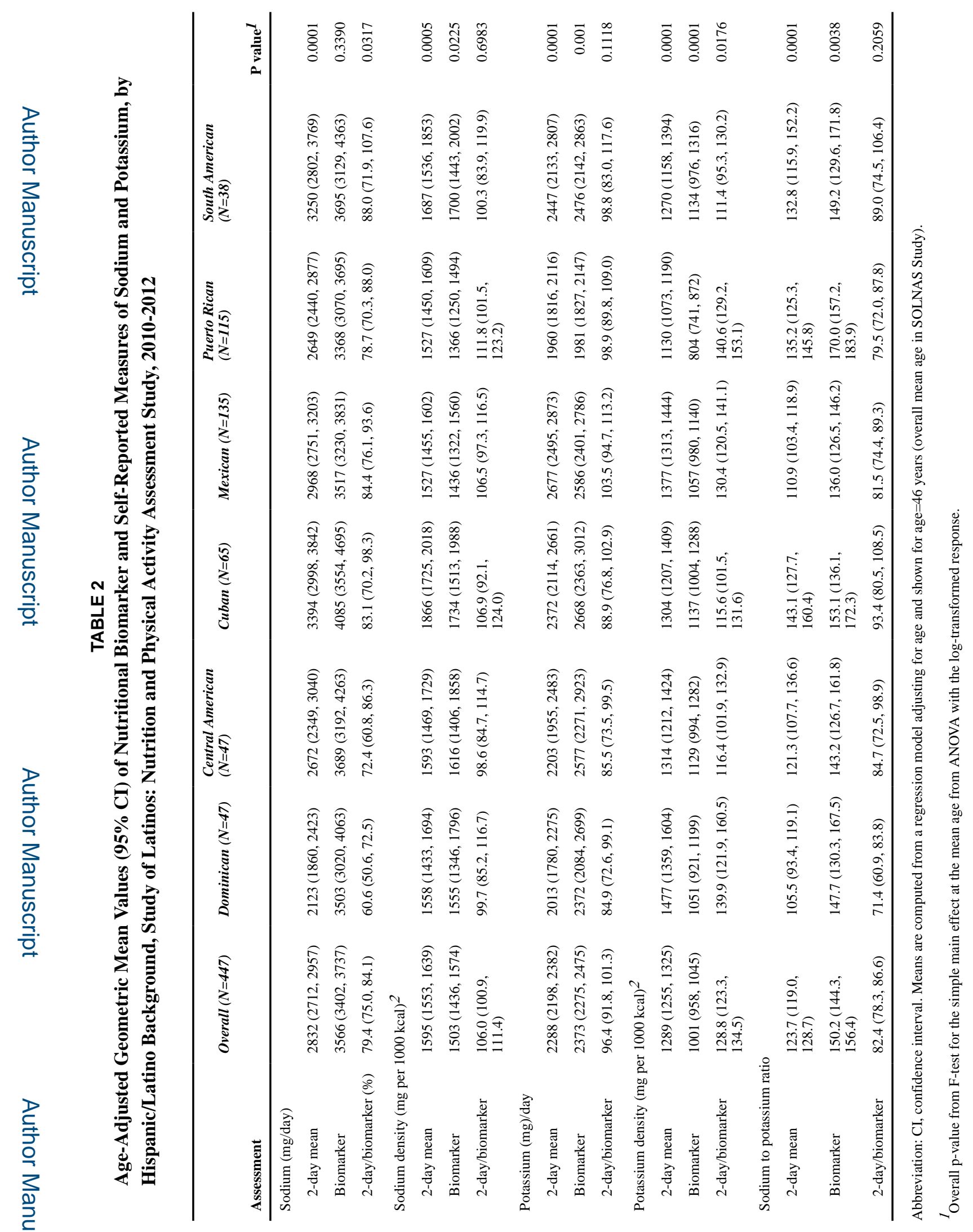

J Hum Hypertens. Author manuscript; available in PMC 2018 January 01. 


\section{Linear Regression of $\log$ (Self-Report) Minus $\log ($ Biomarker) on Predictors for Sodium and Potassium, Study of Latinos: Nutrition and Physical Activity Assessment Study 2010-2012}

\begin{tabular}{|c|c|c|c|c|}
\hline & \multicolumn{2}{|c|}{$\begin{array}{c}\text { Sodium: } \log (\text { self-reported/biomarker) } \\
N=435\end{array}$} & \multicolumn{2}{|c|}{$\begin{array}{r}\text { Potassium: } \log \text { (self-reported/biomarker) } \\
N=435\end{array}$} \\
\hline & Estimate \pm s.e. & P-value ${ }^{1}$ & Estimate \pm s.e. & $P$-value ${ }^{1}$ \\
\hline Intercept & $-0.0403 \pm 0.274$ & 0.883 & $0.0203 \pm 0.238$ & 0.932 \\
\hline Age at parent study baseline & & 0.350 & & 0.256 \\
\hline $25-39$ vs. $<25$ & $-0.1343 \pm 0.130$ & 0.303 & $-0.0280 \pm 0.113$ & 0.805 \\
\hline $40-54$ vs. $<25$ & $-0.2015 \pm 0.125$ & 0.109 & $-0.0311 \pm 0.109$ & 0.775 \\
\hline $55-74$ vs. $<25$ & $-0.2396 \pm 0.141$ & 0.090 & $-0.1655 \pm 0.123$ & 0.178 \\
\hline Sex (Female vs. Male) & $0.0229 \pm 0.066$ & 0.728 & $-0.0018 \pm 0.057$ & 0.975 \\
\hline BMI group & & $<0.001$ & & 0.005 \\
\hline Overweight vs. normal/underweight & $-0.1845 \pm 0.083$ & 0.026 & $-0.1269 \pm 0.072$ & 0.079 \\
\hline Obese vs. normal/underweight & $-0.3377 \pm 0.084$ & $<0.001$ & $-0.2332 \pm 0.073$ & 0.001 \\
\hline Background & & 0.041 & & 0.495 \\
\hline Central American vs. Mexican & $-0.1120 \pm 0.111$ & 0.312 & $-0.1329 \pm 0.096$ & 0.168 \\
\hline Dominican vs. Mexican & $-0.3142 \pm 0.109$ & 0.004 & $-0.1751 \pm 0.095$ & 0.066 \\
\hline Cuban vs. Mexican & $0.0040 \pm 0.112$ & 0.971 & $-0.0865 \pm 0.097$ & 0.376 \\
\hline Puerto Rican vs. Mexican & $-0.1552 \pm 0.089$ & 0.082 & $-0.0725 \pm 0.078$ & 0.350 \\
\hline South American vs. Mexican & $0.0059 \pm 0.117$ & 0.960 & $-0.0402 \pm 0.102$ & 0.694 \\
\hline Language (English vs. Spanish) & $0.1055 \pm 0.085$ & 0.217 & $0.0463 \pm 0.074$ & 0.533 \\
\hline Income & & 0.258 & & 0.350 \\
\hline$\$ 10,000-\$ 20,000$ vs. $<\$ 10,000$ & $0.0260 \pm 0.095$ & 0.784 & $-0.0274 \pm 0.082$ & 0.740 \\
\hline$\$ 20,000-\$ 40,000$ vs. $<\$ 10,000$ & $-0.0338 \pm 0.099$ & 0.732 & $-0.1128 \pm 0.086$ & 0.189 \\
\hline$\$ 40,000-\$ 50,000$ vs. $<\$ 10,000$ & $-0.0822 \pm 0.138$ & 0.551 & $-0.1305 \pm 0.120$ & 0.277 \\
\hline$\$ 50,000-\$ 75,000$ vs. $<\$ 10,000$ & $0.2394 \pm 0.170$ & 0.159 & $-0.0429 \pm 0.148$ & 0.772 \\
\hline $2 \$ 75,000$ vs. $<\$ 10,000$ & $-0.1661 \pm 0.220$ & 0.450 & $-0.1181 \pm 0.191$ & 0.537 \\
\hline Missing Vs. $<\$ 10,000$ & $-0.1950 \pm 0.135$ & 0.151 & $-0.2434 \pm 0.118$ & 0.039 \\
\hline Employment & & 0.480 & & 0.665 \\
\hline Retired vs. employed full-time & $0.1584 \pm 0.131$ & 0.228 & $0.1078 \pm 0.114$ & 0.345 \\
\hline Unemployed vs. employed full-time & $0.1007 \pm 0.083$ & 0.227 & $-0.0259 \pm 0.072$ & 0.721 \\
\hline Part-time vs. employed full-time & $0.1199 \pm 0.096$ & 0.214 & $-0.0188 \pm 0.084$ & 0.823 \\
\hline Education & & 0.962 & & 0.718 \\
\hline $\begin{array}{l}\text { High school or equivalent (GED) vs. less than } \\
\text { high school }\end{array}$ & $-0.0166 \pm 0.082$ & 0.840 & $-0.0301 \pm 0.071$ & 0.674 \\
\hline $\begin{array}{l}\text { Trade/vocational school vs. less than high } \\
\text { school }\end{array}$ & $0.0098 \pm 0.100$ & 0.922 & $-0.0944 \pm 0.087$ & 0.280 \\
\hline University/college vs. less than high school & $0.0264 \pm 0.081$ & 0.746 & $-0.0077 \pm 0.071$ & 0.914 \\
\hline Alcohol & & 0.223 & & 0.119 \\
\hline Low use vs. none & $-0.0487 \pm 0.064$ & 0.450 & $-0.1037 \pm 0.056$ & 0.065 \\
\hline High use $v s$. none & $0.1946 \pm 0.149$ & 0.192 & $0.0527 \pm 0.129$ & 0.684 \\
\hline
\end{tabular}




\begin{tabular}{|c|c|c|c|c|}
\hline & \multicolumn{2}{|c|}{$\begin{array}{c}\text { Sodium: } \log (\text { self-reported/biomarker) } \\
N=435\end{array}$} & \multicolumn{2}{|c|}{$\begin{array}{r}\text { Potassium: } \log \text { (self-reported/biomarker) } \\
N=435\end{array}$} \\
\hline & Estimate \pm s.e. & $P$-value 1 & Estimate \pm s.e. & $P$-value $I$ \\
\hline Smoking status (Current vs. Never/Previous) & $0.0525 \pm 0.081$ & 0.515 & $0.0294 \pm 0.070$ & 0.675 \\
\hline Physical activity level & & 0.156 & & 0.927 \\
\hline Low $v s$. inactive & $-0.2032 \pm 0.106$ & 0.055 & $0.0387 \pm 0.092$ & 0.674 \\
\hline Medium vs. inactive & $-0.1779 \pm 0.113$ & 0.115 & $0.0612 \pm 0.098$ & 0.533 \\
\hline High $v s$. inactive & $-0.1230 \pm 0.076$ & 0.104 & $0.0249 \pm 0.066$ & 0.705 \\
\hline Restaurant score ${ }^{b}$ & $0.0232 \pm 0.012$ & 0.051 & $0.0278 \pm 0.010$ & 0.007 \\
\hline Hispanic/American food & & 0.469 & & 0.738 \\
\hline Mainly Hispanic food vs. American & $0.0958 \pm 0.074$ & 0.196 & $-0.0032 \pm 0.064$ & 0.960 \\
\hline Mostly Hispanic/Latino food vs. American & $0.0201 \pm 0.087$ & 0.818 & $-0.0186 \pm 0.076$ & 0.807 \\
\hline $\begin{array}{l}\text { Equal Hispanic and American food vs. } \\
\text { American }\end{array}$ & $-0.0830 \pm 0.149$ & 0.577 & $-0.1421 \pm 0.129$ & 0.272 \\
\hline Fast food & & 0.605 & & 0.181 \\
\hline Never $v s . ~ \geq 3$ times/week & $0.2185 \pm 0.167$ & 0.190 & $0.3136 \pm 0.145$ & 0.031 \\
\hline$<1$ time a week $v s . \quad 23$ times/week & $0.1868 \pm 0.143$ & 0.193 & $0.2019 \pm 0.125$ & 0.106 \\
\hline 1-2 times a week vs. $\geq 3$ times/week & $0.1488 \pm 0.134$ & 0.267 & $0.1945 \pm 0.117$ & 0.096 \\
\hline$\%$ home meals ( $\geq 75 \%$ vs. $<75 \%$ ) & $-0.0454 \pm 0.070$ & 0.517 & $0.0401 \pm 0.061$ & 0.511 \\
\hline Supplement use (yes vs. no) & $-0.0418 \pm 0.062$ & 0.504 & $-0.1358 \pm 0.054$ & 0.013 \\
\hline Beta-blockers use (yes Vs. no) & $-0.1054 \pm 0.167$ & 0.528 & $-0.1195 \pm 0.145$ & 0.410 \\
\hline Calcium channel blockers use (yes vs. no) & $0.0089 \pm 0.174$ & 0.959 & $0.0276 \pm 0.152$ & 0.855 \\
\hline Anti-hypertensives use (yes vs. no) & $0.1406 \pm 0.115$ & 0.221 & $0.1676 \pm 0.100$ & 0.094 \\
\hline Diuretics use (yes vs. no) & $-0.0278 \pm 0.147$ & 0.850 & $-0.0829 \pm 0.128$ & 0.516 \\
\hline
\end{tabular}

${ }^{1}$ For categorical variables with 3 or more levels, the p-value is shown first for the overall test for the effect of the variable, followed by the coefficient-level p-values;

Bolded $\mathrm{p}$ values are statistically significant.

2 Restaurant score centered at 5.3. Higher values indicate more frequently going out to eat or bringing home ready-to-eat foods. 


\section{Regression calibration coefficients for log-transformed biomarker for sodium and potassium intake, Study of Latinos: Nutrition and Physical Activity Assessment Study, 2010-2012}

\begin{tabular}{|c|c|c|c|c|}
\hline & \multicolumn{4}{|c|}{ Outcome (log BIOMARKER) } \\
\hline & \multicolumn{2}{|c|}{$\begin{array}{c}\text { Sodium }(n=446) R \text {-square }=0.197 \text { Adjusted } \\
R \text {-square }{ }^{1}=0.595\end{array}$} & \multicolumn{2}{|c|}{$\begin{array}{r}\text { Potassium (n=446) } R \text {-square }=0.250 \text { Adjusted } \\
R \text {-square }{ }^{I}=0.617\end{array}$} \\
\hline & $\beta \pm$ s.e. & P Value & $\beta \pm$ s.e. & $P$ Value \\
\hline Intercept & $8.2672 \pm 0.163$ & $<0.001$ & $7.6877 \pm 0.090$ & $<0.001$ \\
\hline $\log$ self-reported sodium 2 & $0.1199 \pm 0.050$ & 0.018 & & \\
\hline Age group & & 0.070 & & 0.022 \\
\hline $25-39$ vs. $<25$ & $0.1028 \pm 0.093$ & 0.271 & $0.0756 \pm 0.083$ & 0.365 \\
\hline $40-54$ vs. $<25$ & $0.1708 \pm 0.088$ & 0.054 & $0.1634 \pm 0.079$ & 0.039 \\
\hline $55-74$ vs. $<25$ & $0.0532 \pm 0.095$ & 0.575 & $0.2242 \pm 0.085$ & 0.008 \\
\hline Sex (female vs. male) & $-0.2764 \pm 0.050$ & $<0.001$ & $-0.1762 \pm 0.042$ & $<0.001$ \\
\hline BMI group & & $<0.001$ & & 0.002 \\
\hline Overweight vs. normal/underweight & $0.1487 \pm 0.062$ & 0.017 & $0.0926 \pm 0.054$ & 0.088 \\
\hline Obese vs. normal/underweight & $0.2966 \pm 0.062$ & $<0.001$ & $0.1885 \pm 0.054$ & $<0.001$ \\
\hline Language (English vs. Spanish) & $-0.0940 \pm 0.054$ & 0.083 & & \\
\hline $\log$ (moderate to vigorous physical activity) & $0.0234 \pm 0.011$ & 0.028 & & \\
\hline Restaurant score ${ }^{2}$ & $-0.0157 \pm 0.008$ & 0.063 & & \\
\hline Fast food & & 0.125 & & \\
\hline Never vs. $\geq 3$ times/week & $-0.2438 \pm 0.121$ & 0.044 & & \\
\hline$<1$ time a week $v s . \quad 33$ times/week & $-0.2436 \pm 0.104$ & 0.020 & & \\
\hline 1-2 times a week vs. $\geq 3$ times/week & $-0.2173 \pm 0.097$ & 0.025 & & \\
\hline Supplement use (yes vs. no) & $0.0854 \pm 0.045$ & 0.059 & $0.1384 \pm 0.040$ & $<0.001$ \\
\hline Log self-reported potassium ${ }^{2}$ & & & $0.1804 \pm 0.049$ & $<0.001$ \\
\hline Hispanic/Latino background & & & & 0.001 \\
\hline Central American vs. Mexican & & & $0.0262 \pm 0.070$ & 0.707 \\
\hline Dominican vs. Mexican & & & $-0.0321 \pm 0.070$ & 0.648 \\
\hline Cuban vs. Mexican & & & $0.0622 \pm 0.064$ & 0.330 \\
\hline Puerto Rican vs. Mexican & & & $-0.1876 \pm 0.055$ & $<0.001$ \\
\hline South American vs. Mexican & & & $-0.0253 \pm 0.075$ & 0.736 \\
\hline Employment status & & & & 0.095 \\
\hline Retired vs. employed full-time & & & $-0.1844 \pm 0.083$ & 0.026 \\
\hline Unemployed vs. employed full-time & & & $-0.0944 \pm 0.049$ & 0.056 \\
\hline Part-time vs. employed full-time & & & $-0.0480 \pm 0.058$ & 0.410 \\
\hline Smoking status (current vs. never/previous) & & & $-0.1175 \pm 0.049$ & 0.018 \\
\hline
\end{tabular}

Abbreviations: BMI, body mass index, SE, standard error

The calibration equations were developed using linear regression models using only SOLNAS data and candidate variables included in backward selection (retained if $\mathrm{p}$-level $\leq 0.1$ ) were: age group, BMI group, gender, language preference, background, income, education, employment status, $\log$ of self-reported moderate to vigorous activity, alcohol use, current smoker, supplement use, restaurant score, type of food, frequency of fast food, high ( $\geq 75 \%$ ) percentage of meals at home, and indicator variables for each of four types of medications that may impact sodium or potassium 
excretion (anti-hypertensives, diuretics, beta blockers and calcium channel blockers.) The model for urinary sodium does not include potassium self-reported intake. The model for urinary potassium does not include sodium self-reported intake.

1

Adjusted ('Prentice') R-square in this table refers to the R-square coefficient adjusted for the within person variability of the urinary biomarker and is calculated as the R-squared divided by the correlation coefficient for the repeated measures of the biomarker from the reliability study (14).

$2 \log$-transformed self-reported sodium centered on mean 7.946905, log-transformed self-reported potassium centered on mean 7.735632, and restaurant score centered at 5.3. Higher values for restaurant score indicate more frequently going out to eat or bringing home ready-to-eat foods. 
TABLE 5

Partial and Adjusted R-squares from Regression Calibration Equations for Sodium and Potassium, Study of Latinos: Nutrition and Physical Activity Assessment Study, 2010-2012

\begin{tabular}{|c|c|c|c|c|}
\hline & \multicolumn{4}{|c|}{ Outcome (biomarker) } \\
\hline & \multicolumn{2}{|c|}{$\begin{array}{c}\text { Sodium (n=446) } R \text {-square }=0.197 \text { Adjusted } R- \\
\text { square }=0.595\end{array}$} & \multicolumn{2}{|c|}{$\begin{array}{c}\text { Potassium }(n=446) \text { R-square }=0.250 \text { Adjusted } R- \\
\text { square }=0.617\end{array}$} \\
\hline & Partial R-square & $\begin{array}{l}\text { Adjusted Partial R- } \\
\text { square }\end{array}$ & Partial R-square & $\begin{array}{l}\text { Adjusted Partial R- } \\
\text { square }\end{array}$ \\
\hline Self-reported sodium & 0.033 & 0.100 & . & . \\
\hline Age group & 0.019 & 0.057 & 0.022 & 0.055 \\
\hline Sex & 0.076 & 0.228 & 0.032 & 0.079 \\
\hline BMI group & 0.038 & 0.113 & 0.016 & 0.038 \\
\hline Language of preference & 0.002 & 0.006 & . & . \\
\hline $\begin{array}{l}\text { Log (moderate to vigorous } \\
\text { physical activity) }\end{array}$ & 0.015 & 0.047 & . & . \\
\hline Restaurant score & 0.001 & 0.002 & . & . \\
\hline Fast food & 0.008 & 0.024 & . & . \\
\hline Supplement use & 0.006 & 0.017 & 0.027 & 0.066 \\
\hline Self-reported potassium & . & . & 0.062 & 0.152 \\
\hline Hispanic/Latino background & . & . & 0.048 & 0.119 \\
\hline Employment status & . & . & 0.024 & 0.060 \\
\hline Smoking status & . & . & 0.019 & 0.047 \\
\hline
\end{tabular}

Abbreviations: BMI, body mass index

Partial R-squares (contribution of each covariate to the variance explained by full model) were computed as R-square from the univariate regression of the outcome on covariate of interest divided by the sum of all univariate R-squares and multiplied by the full model R-squared.

Adjusted ('Prentice') full model and partial R-square were computed by dividing the corresponding R-square by the correlation coefficient between repeated measurements from the repeatability study for the urinary biomarker (14). 